\title{
Regulação do Mercado de Capitais e Desenvolvimento Empresarial no Brasil
}

\author{
http://dx.doi.org/10.21527/2237-6453.2019.47.81-101
}

Recebido em: 6/6/2017

Aceito em: 18/12/2018

\section{Ariana Inês Sachett ${ }^{1}$, Heron Sergio Moreira Begnis ${ }^{2}$}

\begin{abstract}
RESUMO
Este estudo tem por finalidade analisar como a evolução do ambiente institucional regulador do mercado de capitais tem influenciado o desenvolvimento empresarial no Brasil. Procurou-se compreender a formação histórica do mercado, assim como a construção de suas instituições e os efeitos da regulação sobre as estruturas de governança das empresas por intermédio do método histórico de investigação. A análise conduziu ao resultado de que as disposições impostas pelo ambiente institucional foram determinantes no desempenho do mercado ao longo do tempo. Em suas origens, as instituições representaram óbices à atividade econômica, culminando no atraso da consolidação da indústria acionária no país. Quando se desenhou o ambiente macroinstitucional do mercado, este passou a constituir uma alternativa às empresas para a economia de custos de transação. Assim, com a instituição da governança corporativa como mecanismo de transparência do sistema acionário, o aprimoramento da gestão se caracteriza como o desenvolvimento empresarial brasileiro.
\end{abstract}

Palavras-chave: Mercado de capitais. Ambiente institucional. Desenvolvimento empresarial.

STOCK MARKETS REGULATION AND BUSINESS IMPROVEMENT IN BRAZIL

\section{ABSTRACT}

This study aimed to analyze how the evolution of the regulatory institutional capital market environment has influenced the business development in Brazil. The research sought to understand the historical development of the market, how their institutions were built, and the effects of regulation on the governance structures of companies through the historical method of investigation. The analysis led to the result that the provisions imposed by the institutional environment were determinants in market performance over time. In their origins, the institutions represented obstacles to economic activity, resulting in the delay of the capital market consolidation. However, when the market's regulatory environment was created, it has become an alternative to companies for transaction cost savings. Therefore, with the implementation of corporate governance as transparency mechanism, the improvement of management is characterized as the development of the Brazilian business scenario.

Keywords: Capital market. Institutional environment. Business improvement.

\footnotetext{
${ }^{1}$ Graduada em Ciências Econômicas pela Universidade de Santa Cruz do Sul (Unisc). ariana_sachett@hotmail.com

${ }^{2}$ Doutor em Agronegócios (Cepan/UFRGS), professor do Programa de Pós-Graduação em Administração da Universidade de Santa Cruz do Sul (PPGA/Unisc). heron@unisc.b
} 
As instituições têm a competência de organizar o meio social e o processo econômico, representando o ambiente definidor da atividade humana e das delimitações do mercado. Diante de tal premissa, o arranjo institucional direciona a eficiência alocativa (ACEMOGLU; ROBINSON, 2012) dos recursos na medida em que ordena as ações dos indivíduos (NORTH, 1990, 2005), suas interações e o custo de funcionamento do mercado em suas transações (COASE, 1937, 1990; WILLIAMSON, 1985, 1996). A análise das instituições culminou no desenvolvimento de pesquisas em torno das interações entre o ambiente político institucional, a estrutura de governança das empresas e o meio jurídico e social em que os agentes econômicos coexistem, principalmente a partir da abordagem da Nova Economia Institucional (NEI). Deste entendimento resulta que, como as instituições estão sujeitas às mudanças impostas pelas interações entre os agentes e às exigências do meio social e produtivo, o arranjo institucional decorre de processos distintos de desenvolvimento econômico mediante o decurso evolutivo das instituições (NORTH, 1990, 2005; HODGSON, 2004; HOFFMAN, 1999).

A partir dessa corrente, a bolsa de valores pode ser considerada um nexo de contratos formais e informais, com o objetivo de coordenar o mercado de ações, promover estímulos, controles e agilizar o fluxo de informações para todos os agentes relevantes, criando um ambiente propício para a melhoria do processo empresarial por meio da economia dos custos de transação. Logo, a governança corporativa no mercado de ações é um meio contínuo de interações entre o ambiente institucional, a estrutura de governança e a sociedade, visando à confiança social perante as instituições econômicas e seu enfoque sobre o desenvolvimento socioeconômico, como é o caso do mercado de ações brasileiro.

O estudo de Forti, Peixoto e Santiago (2009), no entanto, conclui que o mercado de capitais no Brasil não alcança o conceito de eficiência em sua totalidade, o que se deve fundamentalmente à presença de assimetria informacional. A questão da assimetria de informações é tema largamente discutido pela NEI, especialmente no tocante à formação de custos de transação e na definição de estruturas de governança. Assim sendo, destaca-se a necessidade de avalição do arranjo regulatório (ambiente institucional) e sua influência sobre o funcionamento do mercado de capitais.

Diante deste quadro, apresenta-se a questão central deste artigo: Como a evolução do ambiente institucional do mercado de capitais tem influenciado o desenvolvimento empresarial no Brasil? Com esse ponto de partida e, por meio do embasamento teórico da NEI, este estudo teve como objetivo analisar as mudanças no mercado de capitais brasileiro e as interações entre o ambiente institucional formal e as firmas que o compõem, procurando identificar sua influência sobre o desenvolvimento empresarial. Para tanto, buscou-se compreender a formação histórica do mercado, como também descrever o processo de construção das instituições formais regulatórias do sistema, a interação entre o mercado de capitais e o ambiente institucional por meio da legislação que o permeou, e, por fim, avaliar os efeitos dessa regulação sobre as estruturas de governança das empresas inseridas nesse contexto. Procurou-se identificar e explicar as forças que influenciaram o desenvolvimento empresarial no Brasil utilizando o método histórico de investigação. 


\section{O AMBIENTE INSTITUCIONAL E O DESEMPENHO ECONÔMICO}

Ao longo do século 20 iniciou-se um novo paradigma nas ciências econômicas, o qual se fundamentou na análise das conexões entre o ambiente institucional e o sistema econômico. Tais bases foram desenvolvidas pela chamada Nova Economia Institucional e estão alicerçadas nos trabalhos de Coase $(1937,1990)$, sobre a origem das firmas e os custos de funcionamento dos mercados, Williamson $(1985,1996)$, solidificando o conceito de Custos de Transação (CT) e das Estruturas de Governança, North (1990, 2005) e, mais recentemente, por Acemoglu e Robinson (2012) em relação às influências do arranjo institucional sobre o desempenho econômico dos países.

Diante da perspectiva de que as instituições são relevantes ao desempenho econômico, entende-se a contribuição dos conceitos da NEI como fundamentais ao que compete o arranjo institucional (NORTH, 1990, 2005; ACEMOGLU; ROBINSON, 2012) e às estruturas de governança (WILLIAMSON, 1985, 1996) das organizações em relação ao mercado de capitais. Por essa razão, detalham-se na sequência os principais argumentos da NEI, as concepções acerca da racionalidade econômica e do comportamento dos agentes, a governança corporativa como elemento resultante do arranjo institucional e as características do mercado de valores mobiliários, em termos de governança e ordenamento jurídico.

\section{A NOVA ECONOMIA INSTITUCIONAL}

A Nova Economia Institucional aborda a importância relativa das instituições sobre o resultado econômico, no qual o arranjo institucional e suas modificações ao longo do tempo influenciam a eficiência alocativa dos sistemas sociais. Assim, a formulação e transformação das instituições conduzem os resultados das ações econômicas ao constituírem restrições ou incentivos à promoção da eficiência (ACEMOGLU; ROBINSON, 2012), delimitando o desenvolvimento das sociedades por meio da evolução histórica das regras formais e informais que a regulam (NORTH, 1990).

O ambiente institucional representa o conjunto de regras sociais, legais e políticas, básicas a qualquer sociedade, as quais estabelecem os fundamentos para a produção, a troca e a distribuição de bens e serviços (WILLIAMSON, 1985). Por isso, o ambiente institucional define os direitos de propriedade, os direitos contratuais e delimitam os fundamentos econômicos das transações (ALCHIAN; DEMSETZ, 1973; COOTER; ULEN, 2010). A NEI, portanto, demonstra como o arranjo institucional pode incentivar ou obstruir a dinâmica econômica, determinando as formas alternativas de governança que as firmas podem aplicar. A abordagem da NEI é construída a partir de uma teoria do comportamento humano, cuja racionalidade é limitada (SIMON, 1976, 2000) e sujeita ao oportunismo (WILLIAMSON, 1985), combinada com uma teoria dos custos de transação (NORTH, 1990). Por meio dessa correlação pode-se entender o papel que as instituições desempenham na sociedade, visto que estas delimitam as interações entre os agentes econômicos e os consequentes resultados das economias (NORTH, 1990).

A abordagem da NEI demonstra que as empresas, os mercados e a relação contratual são instituições econômicas importantes, as quais representam o produto do processo evolutivo das inovações organizacionais. Nesse ponto, as instituições propiciam confiabilidade às decisões alocativas, conduzindo à eficácia na aplicação dos recursos 
e à redução dos custos de transação. Conforme Coase (1937), a firma aplica seus processos por meio da coordenação contratual, desenhando suas atividades a partir dos arranjos institucionais impostos pelos agentes econômicos. Por essa razão, o modo de governança da empresa revela como esta percebe os riscos potenciais do ambiente institucional ao estabelecer ações estratégias em suas estruturas internas (WILLIAMSON, 1996), visando à redução das friç̧ões do sistema econômico (WILLIAMSON, 1985) impostas aos contratos e aos direitos de propriedade (ALCHIAN; DEMSETZ, 1973). Dessa forma, as empresas estão sujeitas a ambientes distintos, contexto em que se tornam necessárias estratégias adequadas à sobrevivência diante da concorrência e, principalmente, às adaptações contínuas impostas pelas instituições regulatórias que moldam o mercado. A partir disso, Williamson (1985) argumenta que a estrutura de governança se desenvolve sob os limites impostos pelo ambiente institucional e pela interferência dos pressupostos comportamentais dos indivíduos.

Em relação aos mecanismos organizacionais da sociedade, o mercado mostrou-se uma instituição econômica fundamental às relações de troca entre os agentes (HAYEK, 1985), porém, a partir dos contextos mercantis distintos, dos custos de transação e das falhas inerentes a esse processo, foi necessária a adaptação de um sistema seletivo de instituições ao longo do desenvolvimento econômico para a promoção da história de cada sociedade (NORTH, 1990). Como as instituições determinam o desempenho das economias, a história econômica permite entender o processo de formação institucional e como tais instituições, condicionadas pelas restrições formais e informais historicamente determinadas, delimitam as escolhas dos agentes e a existência e intensidade dos custos de transação.

\section{RACIONALIDADE ECONÔMICA E A GOVERNANÇA CORPORATIVA}

A abordagem de Simon (1976) reconhece que, embora o indivíduo condicione o seu comportamento à razão, existem limites a sua capacidade de processar informações e racionalizar sobre suas ações. Tal afirmação identifica que os contratos efetuados são incompletos, pois não é possível prever todas as contingências futuras da transação, e que estes necessitam do arranjo institucional para identificar alternativas que amenizam os custos da interação humana e a possibilidade de condutas oportunistas ou escolhas ineficientes.

Isso posto, as transações não são reguladas exclusivamente pelo sistema de preços, mas também pelos mecanismos que se encontram lastreados nos contratos (COASE, 1937; CHEUNG, 1983). Por isso, as organizações econômicas representam a coordenação contratual que reflete as limitações impostas pelo ambiente institucional e por seus objetivos estratégicos (ZYLBERSZTAJN; SZTAJN, 2005). As formas alternativas de coordenação, por meio da governança, trazem resultados diferentes para as organizações. É nesse ambiente que os contratos definem o padrão comportamental e as decisões alocativas a partir dos diferentes custos de transação e da escolha das estruturas de governança.

A eficiência da atividade empresarial, portanto, decorre da aptidão das companhias em criar mecanismos de governança (WILLIAMSON, 1996) na busca pela sustentação no mercado competitivo. A captação de recursos via mercado de capitais oferece financiamentos menos onerosos, por isso, para aprimorar as relações entre as firmas 
e os investidores, surge a governança corporativa como forma de proporcionar maior confiabilidade à capitalização de recursos e segurança do investimento (SOUZA, 2005). O sistema de governança adotado, entretanto, depende do ambiente institucional, pois as instituições condicionam a formação do mercado de capitais, como também do grau de proteção aos investidores, o que acaba por influenciar a trajetória do desenvolvimento empresarial (SILVA, 2006).

A estrutura de governança aplicada nas organizações econômicas, portanto, representa o produto da evolução de como as firmas aprenderam a agir em um ambiente específico (ANTONACOPOULOU; CHIVA, 2007; CROSSAN; LANE; WHITE, 1999; GHERARDI, 2006; PETTIGREW, 1987). Com a maior complexidade das relações, os ciclos das economias passaram a demandar inovações, em que a governança se adequou às exigências para conduzir à eficiência da tomada de decisão, propiciar a economia dos custos de transação e o desenvolvimento empresarial conforme as disposições do ambiente institucional. Da mesma forma, segundo Carvalho (2009), as características institucionais inerentes ao ambiente acabam por interferir na possibilidade das empresas em acessar fontes de financiamento, o que depende do nível de desenvolvimento institucional ao qual a firma está submetida. A melhora nas instituições pode ser um mecanismo para aliviar a repressão financeira, pois o baixo desenvolvimento institucional faz com que as empresas tenham de limitar seus investimentos (CARVALHO, 2009), o que reforça o argumento da influência do ambiente institucional do mercado de capitais sobre o desenvolvimento empresarial.

\section{MERCADO DE VALORES MOBILIÁRIOS: A Governança e o Ordenamento Jurídico}

O crescimento do mercado de ações condiz com uma inovação organizacional, pois este facilita a mobilização de capital canalizando-o às empresas que necessitam de recursos para crescer e prosperar, o que torna o mercado de capitais o lócus central da intermediação de recursos de longo prazo (TORRES FILHO; COSTA, 2013) e fortalece a função primária das instituições financeiras em melhorar a alocação de recursos (MAYER, 2002). Nesse sentido, embora a negociação de ações nas bolsas de valores esteja relacionada com a capacidade empresarial de criar valor, a lógica que ocorre no mercado de capitais é diferente do que acontece internamente à organização. Por isso, o papel da propriedade na estrutura de governança é ligar as fontes de capital no mercado com o processo interno da empresa para garantir a segurança do investimento (CARLSSON, 2001).

Um acionista, por exemplo, pode vender suas ações sempre que achar necessário, conforme as avaliações de suas perspectivas futuras, porém a empresa está condicionada às decisões definidas anteriormente, devido à mobilização de recursos e ao tempo demandado de maturação do investimento. Tal perspectiva vem ao encontro do conceito de path dependence, no qual a trajetória histórica é determinante ao limitar as decisões futuras, mediante o grau de sensibilidade em que ocorre a dependência das decisões anteriores (ARTHUR, 1994; LIEBOWITZ; MARGOLIS, 1995; PIERSON, 2000).

Com o desenvolvimento das relações entre as companhias e os investidores, inseriu-se o movimento da governança corporativa no mercado de capitais (SOUZA, 2005), o que reforçou a relação entre o sistema financeiro e as empresas ao criar arranjos ins- 
titucionais para gerar incentivos aos agentes econômicos, disciplinar a gestão da organização, melhorar o fluxo de informações e aproximar a propriedade do capital com o controle da firma (MAYER, 2002). O surgimento da governança corporativa representou uma nova lógica institucional (ZAJAC; WESTPHAL, 2004), em que esta corresponde a um conjunto de princípios e práticas que visam a minimizar os potenciais conflitos de interesse entre os diferentes agentes, reduzir o custo de capital e aumentar o valor da empresa, incrementando o retorno do investimento e fortalecendo o mercado nacional (SILVA, 2006). Pelo fato de a estrutura de governança estar condicionada ao ambiente institucional em que se encontra a firma, os modelos de governança variam de país para país (SZTAJN; GORGA, 2005), destacando-se que, para qualquer mercado em crescimento, as práticas de boa governança são fundamentais à redução do custo de capitação de recursos (VIEIRA; MENDES, 2004).

Em relação à governança corporativa, os modelos de estrutura do mercado de capitais estão vinculados às instituições jurídicas dispostas na sociedade. Além das tradições institucionais, "a história específica de cada país põe sua própria marca no direito" (COOTER; ULEN, 2010, p. 77), o que promove processos distintos de organização social. Conforme Sztajn e Gorga (2005), isso ocorre porque as estruturas sociais e os valores sobre os quais estas se fundam são diferentes (ACEMOGLU; ROBINSON, 2012), o que conduz as instituições e os costumes locais a partir do arranjo disposto nos ordenamentos.

Assim, os mercados de capitais supostamente deveriam encontrar-se diante de modelos de governança baseados nas características socioeconômicas dos países, na sua formação histórica e no estabelecimento da tradição de direito específica à sociedade em questão. Por essa razão ocorre a dificuldade em se transpor os princípios da governança corporativa original para os demais arranjos sociais dispostos no mundo (SZTAJN; GORGA, 2005). Por conseguinte, para analisar a aplicabilidade das formas alternativas de governança corporativa no mercado de capitais, faz-se necessária a compreensão das interações entre o ambiente institucional e a formulação das estruturas de governança das firmas.

\section{A EVOLUÇÃO INSTITUCIONAL DO MERCADO DE CAPITAIS BRASILEIRO}

A partir da análise institucional, o processo de desenvolvimento econômico de uma sociedade pode ser vinculado à evolução histórica de suas instituições (ACEMOGLU; ROBINSON, 2012; NORTH, 1990, 2005; HODGSON, 2004; HOFFMAN, 1999). Assim sendo, para compreender os efeitos do arranjo institucional sobre o desenvolvimento empresarial mostrou-se necessário caracterizar as origens que influenciaram a efetivação do mercado de capitais no Brasil, sua consolidação e a adaptação contínua de suas instituições.

\section{Os Entraves ao Processo Reformador}

O surgimento do mercado de capitais no Brasil está relacionado ao processo de formação econômica e jurídica do país. Durante a etapa colonial eram impostos à Colônia limites institucionais, políticos e econômicos em relação às suas transações, ao desenvolvimento de conhecimentos e indústrias internas, como também à restrição ao comércio exterior (FURTADO, 2007). Tais fatos indicam que não se fazia necessário um 
mercado de capitais para financiar as empresas. Mesmo após a independência política em 1822, o Brasil mantinha-se dependente economicamente e, sobretudo, ligado aos aspectos estruturais da economia colonial (FURTADO, 2007), o que condicionou o desenvolvimento socioeconômico nacional, além de delimitar a origem do mercado de valores mobiliários.

O mercado de capitais brasileiro não apresentou um desenvolvimento significativo até 1965 devido, principalmente, ao ambiente inflacionário, responsável pela concentração das transações em poucas ações. Também em virtude da má organização das bolsas, o que possibilitava a manipulação, do monopólio dos corretores públicos, da forma de atuação das sociedades de investimento, de uma legislação inadequada, a qual não resguardava os direitos dos acionistas minoritários e de uma tributação penalizava o mercado, com impostos excessivos sobre os rendimentos (MACARINI, 2008). Nesse contexto, até 1965 não havia uma regulação sobre o mercado de capitais por parte de um órgão específico, apenas os fatores macroinstitucionais ligados à legislação brasileira sobre a atividade de corretagem, instalação e funcionamento das sociedades anônimas, como também os elementos microinstitucionais conectados aos costumes da esfera jurídica e comercial.

Conforme Carvalho (2014), a origem do mercado de capitais brasileiro está caracterizada pela ação dos comerciantes, os quais baseavam seu comportamento segundo a tradição das práticas comerciais, mediante as imposições legais que foram sendo construídas. Com isso, o ambiente institucional ligado às instituições formais de leis, acordos contratuais dos estatutos das empresas e das operações de corretagem são os elementos que condicionaram a estrutura de governança das companhias brasileiras que, aliados às instituições informais dos costumes, tradições e padrões de conduta, determinaram as transações e o comportamento dos agentes. Para Vieira e Mendes (2004), a formação das empresas no Brasil e o seu desenvolvimento até o século 20 ocorreram com base no controle familiar, mediante uma estrutura de capital pouco alavancada, cuja administração era feita pelos proprietários. Desse modo, com o crescimento das organizações e expansão dos negócios, surgiu a necessidade de crédito e de uma estrutura de capital que permitisse o aumento da escala produtiva (VIEIRA; MENDES, 2004).

Durante o século 19, as transformações das relações de produção promoveram condições ao fomento do processo produtivo. A partir da institucionalização da Junta dos Corretores, seguida da elaboração do Código Comercial e da reorganização do Banco do Brasil, observa-se uma fase de prosperidade (LEVY, 1977). Dessa forma, ao longo da segunda metade do século 19, desenvolveram-se novas empresas na medida em que se alterava a pauta de importações (FURTADO, 2007; SUZIGAN, 1986; VERSIANI; BARROS, 1978), em que cessava o tráfico de escravos e se exigia mais das máquinas (LEVY, 1977). Apesar da prosperidade, a vulnerabilidade da economia manifestou-se em 1857 devido a uma crise de liquidez e por uma crise comercial, fatos que, segundo Levy (1977), provocaram a perda de eficiência no mercado financeiro.

Em uma reação conservadora ao liberalismo do Código Comercial e às iniciativas do empresariado foi imposta, após a crise de 1857, a obrigatoriedade cartorial da intervenção dos corretores nos negócios empresariais (CARVALHO, 2014). Desse modo, surge a Lei 1.083/1860, como uma legislação que dificultava a criação das sociedades 
anônimas, passando a ser conhecida como a Lei dos Entraves. O maior objetivo do regulamento era evitar a disseminação de novas empresas com capital aberto, tornando obrigatória a intervenção de um corretor e autorização prévia do governo para seu funcionamento (CARVALHO, 2014). Posteriormente, com a revogação da Lei dos Entraves em 1882, Levy (1977) considera que as operações na Bolsa estão na raiz da transformação do processo produtivo e se desenvolveram de forma conjunta à expansão do comércio do café, ao aumento do volume de moeda circulante e à ampliação dos horizontes de acumulação mundial.

Os fatos históricos ocorridos nas últimas décadas do século 19 representaram uma importante fase na História brasileira. A Abolição da Escravidão (1888) demonstrou uma ruptura econômica, favorecendo o surgimento de uma onda de otimismo sobre a sociedade. Em sequência, a Proclamação da República (1889) conduziu à alteração do regime de trabalho e do sistema político. A expectativa originada desses eventos aumentou rapidamente o volume de negócio. Esses fatos promoveram a fase especulativa chamada de "Encilhamento" (LEVY, 1980; TAUNAY, 1893), configurada por uma política econômica que procurou injetar dinheiro na economia e incentivar a industrialização por meio do estímulo ao investimento acionário (BARCELLOS, 2010).

O Encilhamento provocou um movimento de especulação na Bolsa de Valores com o surgimento de um mercado informal no qual eram negociadas ações fora do seu recinto. Diante do cenário de otimismo da sociedade, o crescimento dos negócios pode ser verificado no Gráfico 1, o qual demonstra que a quantidade de operações dispostas entre ações, debêntures e letras hipotecárias na Bolsa de Valores do Rio de Janeiro aumentou consideravelmente. Apesar do crescimento, este se deu de forma desordenada, o que culminou na retração difundida pelo Encilhamento, em virtude da crise especulativa de 1891. Segundo Carvalho (2014), a especulação do mercado provocou quedas significativas de preços, resultando em inúmeros prejuízos e na crise financeira. Após a especulação, iniciou-se a formatação de uma legislação que evitasse um episódio semeIhante, limitando as operações no mercado. As alterações regulatórias levaram a uma conjuntura semelhante ao ambiente restritivo da Lei dos Entraves, garantindo aos corretores uma reserva de mercado e o monopólio na sua intermediação.

Gráfico 1 - Movimento da Bolsa de Valores do Rio de Janeiro 1850-1893

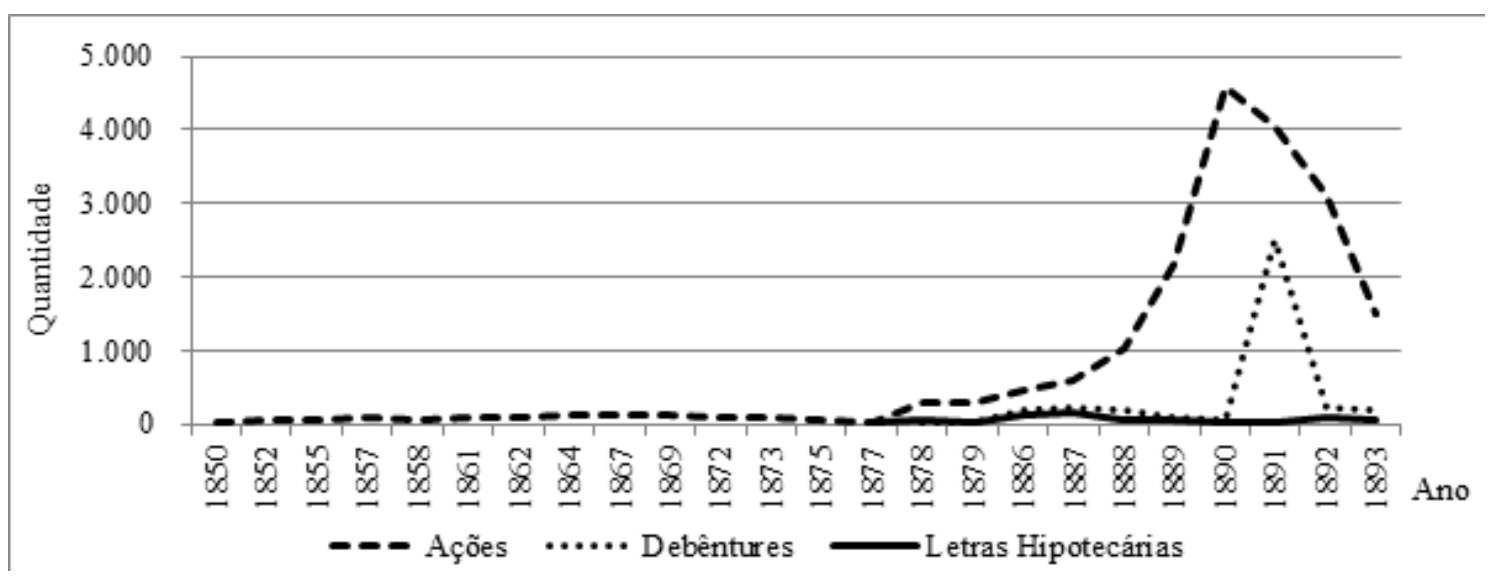

Fonte: Elaborado pelos autores com base nos dados de Levy (1977). 
Ao longo do século 19 o mercado de capitais brasileiro não detinha um ambiente regulador estruturado, o que facilitou a especulação. Ainda, diante da queda das Bolsas, preços e transações nos momentos de crise, não foi estabelecido um ambiente regulatório que promovesse os limites institucionais das conexões econômicas e o crescimento ordenado do mercado como fonte de captação de recursos para as empresas. Em contraposição, nas duas situações de crise, foram instituídas normas formais (leis) que se tornaram empecilhos à expansão e fortalecimento do mercado de capitais no Brasil, visto que eram óbices às operações na medida em que se tornou obrigatória a intermediação de um corretor. Tais condições levaram a um ambiente institucional que restringia as interações econômicas, promovendo o monopólio das operações aos corretores vitalícios, a atrofia da atividade econômica e a impossibilidade de uma organização eficiente do mercado por meio das estruturas de governança para, assim, economizar os custos de transação e garantir a eficácia no processo de tomada de decisão empresarial, conforme os argumentos de Coase (1937).

Por essas razões, o desenvolvimento empresarial mediante a captação de recursos via mercado acionário não se mostrou significativo até meados do século 20 . É possível entender, com base nos argumentos trazidos pela $\mathrm{NEI}$, que muito possivelmente esta condição tenha sido determinada devido ao estancamento das operações como resultado da exclusividade cartorial e das instituições legais impostas após a crise do Encilhamento, as quais são apresentadas de forma sintética no Quadro 1.

Quadro 1 - Principais Legislações do Mercado de Capitais no Brasil 1500-1963

\begin{tabular}{|c|c|c|c|c|c|c|}
\hline $\mathbf{1 8 4 5}$ & $\mathbf{1 8 5 0}$ & $\mathbf{1 8 6 0}$ & $\mathbf{1 8 8 2}$ & $\mathbf{1 8 9 1}$ & $\mathbf{1 8 9 5}$ & $\mathbf{1 9 4 6}$ \\
\hline $\begin{array}{c}\text { Decreto } \\
\text { n. } 417\end{array}$ & Lei n. 556 & $\begin{array}{c}\text { Lei n. } \\
1.083\end{array}$ & Lei n. 3.150 & $\begin{array}{c}\text { Decreto } \\
\text { n. } 1.362\end{array}$ & $\begin{array}{c}\text { Decreto } \\
\text { Legislativo } \\
\text { n. 354 }\end{array}$ & $\begin{array}{c}\text { Decreto Lei } \\
\text { n. } 9.783\end{array}$ \\
\hline $\begin{array}{c}\text { Regulação } \\
\text { sobre a } \\
\text { atividade dos } \\
\text { corretores }\end{array}$ & Código & Lei dos & $\begin{array}{c}\text { Revoga as } \\
\text { restrições } \\
\text { sobre as } \\
\text { S/A }\end{array}$ & $\begin{array}{c}\text { Cria um imposto } \\
\text { sobre as } \\
\text { operações futuras } \\
\text { do Encilhamento }\end{array}$ & $\begin{array}{c}\text { Reorganiza a } \\
\text { corporação dos } \\
\text { corretores de } \\
\text { forma restrita }\end{array}$ & $\begin{array}{c}\text { Registro } \\
\text { obrigatório } \\
\text { das S/A na } \\
\text { Bolsa }\end{array}$ \\
\hline
\end{tabular}

Fonte: Elaborado pelos autores.

Em relação à legislação imposta nesse período, tais normas restringiram a ação do mercado de capitais, o que vai de encontro à afirmação de que a negligência benigna do governo é a melhor prática para os países em estágio inicial de desenvolvimento econômico, visto a retenção das transações por meio de inúmeros regulamentos, pois um mercado de ações excessivamente regulado e mal planejado conduz ao seu subdesenvolvimento (STRINGHAM; BOETTKE; CLARK, 2008). Em virtude de mudanças tópicas ao longo do tempo, a regulamentação incorporada após a crise financeira de 1857 esteve em vigor até a Lei do Mercado de Capitais, em 1965. Assim, sem considerar o período do Encilhamento, a Lei dos Entraves de 1860 foi efetiva por mais de cem anos, a qual criou o monopólio dos corretores oficiais na negociação de títulos públicos, como também promoveu os condicionantes do mercado de capitais brasileiro no século 20.

Apenas com a construção da base industrial no final da década de 50 que o mercado de ações passou a ter condições de crescimento. Em meio ao ambiente de instabilidade econômica e de agitação política no início dos anos 60, começam a surgir medidas 
para incentivar o mercado de capitais e lhe dar estabilidade, assim como reformulações nas leis que tratavam das sociedades anônimas e da organização das Bolsas. De acordo com Barcellos (2010), apenas em 1965 ocorre o marco de aperfeiçoamento institucional do mercado, a Lei n. 4.728 (Lei do Mercado de Capitais), elemento essencial ao início da regulação do mercado acionário brasileiro.

Desse modo, o funcionamento das Bolsas brasileiras foi desde a liberdade de seus membros, passando pelas restrições dos regulamentos do final do século 19, até a exclusividade cartorial que impedia a expansão do mercado (CARVALHO, 2014). Sob a ótica institucional, foi apenas com a Lei do Mercado de Capitais, em 1965, que as Bolsas passaram a expandir sua atuação junto as estruturas de governança das firmas. O aprendizado histórico do que beneficia os investidores é essencial para economias em estágio inicial de desenvolvimento, porém os mercados de ações que são excessivamente regulados e mal planejados trazem como resultado o seu subdesenvolvimento (STRINGHAM; BOETTKE; CLARK, 2008). Tal relação entre o sistema financeiro, arranjos de governança, sistemas jurídicos, processo de investimento e o crescimento econômico demonstram que as políticas que promovem o desenvolvimento institucional com ênfase na proteção ao investidor, em particular o minoritário, acabam por engajar o desenvolvimento financeiro e em consequência o desenvolvimento empresarial (MAYER, 2002). Nesse sentido, o quadro jurídico é fundamental para explicar o comportamento financeiro das empresas e investidores, em que a proteção ao investimento promove o desenvolvimento financeiro, o que, por sua vez, acelera o crescimento econômico (CASSIMON; ENGELEN, 2005).

Nesse contexto, se o quadro jurídico é inadequado para as empresas alcançarem sua arquitetura financeira ideal, existe a impossibilidade de oportunidades de crescimento ou opções reais para as firmas, gerando um nível menor de crescimento econômico e afetando as empresas que necessitam do mercado de capitais como fonte de recursos externos (CASSIMON; ENGELEN, 2005). Por essa razão, a arquitetura do mercado determina sua dinâmica, em que as estruturas institucionais impactam sobre o sistema financeiro juntamente com a interação do comportamento dos agentes, com a eficiência alocativa sendo determinada por essa relação (BOTTAZZI; DOSI; REBESCO, 2005). Assim, o desenvolvimento financeiro contribui para o crescimento econômico, com o mercado de capitais constituindo o elemento principal ao financiamento externo da empresa (MAYER, 2002).

\section{A Consolidação Institucional}

$\mathrm{Na}$ história do mercado de capitais brasileiro é possível identificar dois quadros institucionais com características e sistemas regulatórios distintos. 0 primeiro cenário corresponde à análise anterior a 1965, em que as particularidades do mercado estão marcadas pelos fatos históricos, econômicos e políticos do século 19. O segundo quadro corresponde ao resultado de constantes evoluções nos aspectos institucionais, sendo estas transformações acumuladas desde 1960, ocasião em que, em paralelo à política de estabilização econômica, um conjunto amplo de reformas no meio institucional foi posto em prática (MACARINI, 2008). Segundo Mattos Filho e Prado (2012), no Brasil, a responsabilidade pela criação, atrofia ou crescimento do mercado acionário pode ser atribuída, em parte, à sua regulamentação jurídica. A partir de 1964 são adotadas 
estratégias regulatórias com o objetivo de transformar o mercado de capitais em uma fonte significativa de recursos de longo prazo para o desenvolvimento das atividades das companhias nacionais, visto que a expectativa da reforma após a criação das bases institucionais era mobilizar um fluxo expressivo de poupança destinado à capitalização empresarial (MACARINI, 2008).

Tendo em vista o panorama de estagflação da economia brasileira, um conjunto de transformações institucionais configurou a reformulação do sistema, iniciando o processo de consolidação do mercado de valores mobiliários no Brasil (MATTOS FILHO; PRADO, 2012). A reforma na regulação do mercado de capitais buscou modernizar as Bolsas, extinguir o monopólio dos corretores vitalícios e criar um sistema de distribuição de valores mobiliários para, assim, desembaraçar a dependência de crédito, principal fator limitante à expansão das empresas (MACARINI, 2008). O cenário empresarial brasileiro, contudo, estava marcado pelo controle familiar, sem interesse em partilhar a tomada de decisão e fornecer informações aos investidores (POSER; ROTH, 1965). Além disso, não existia a cultura de aplicação em capitais pela sociedade, a qual preferia o mercado imobiliário e as letras de câmbio como forma de investimento, visto que o mercado de capitais era pouco desenvolvido e o ambiente inflacionário não atraía a presença ativa do pequeno investidor (MACARINI, 2008). Por essas razões, as reformas institucionais de 1964 e 1965 não foram suficientes para desenvolver o mercado de capitais como o esperado, sendo necessário incentivos tributários de forma paralela às mudanças institucionais (MATTOS FILHO; PRADO, 2012).

Durante a consolidação das instituições regulatórias do mercado de capitais ainda prevaleciam os aspectos de assimetria informacional e racionalidade econômica limitada dos agentes, uma vez que o processo de seleção das alternativas de comportamento, como argumentado por Simon (1976), estava condicionado a um cenário empresarial familiar, com pouco interesse em divulgar informações da tomada de decisão da firma para os investidores. Da mesma forma, nas estruturas de governança das empresas nacionais, não existiam elementos ligados ao conjunto de processos e padrões de conduta corporativa, limitando a transparência dos resultados e intensificando a racionalidade limitada dos agentes econômicos. Assim, os riscos oriundos do comportamento oportunista e da possibilidade de quebras contratuais que Williamson (1985) sinaliza eram significativos no cenário do mercado brasileiro. Mesmo com a incipiente estruturação de um ambiente regulatório das transações, o mercado de ações ainda não promovia níveis de confiança exigidos pelos agentes econômicos.

A reforma legislativa de 1965 determinava, pela primeira vez na História, a regulação da Bolsa e dos corretores, característica distinta da antiga vinculação com os Ministérios e Secretarias Estaduais de Fazenda, que até então vigorava (CARVALHO, 2014). Isto representa um avanço institucional à medida que tira o elemento regulatório do campo da política, levando-o para a esfera técnica. A partir da Lei do Mercado de Capitais, as Bolsas de Valores passaram a ter autonomia administrativa, financeira e patrimonial, operando sob a supervisão do Banco Central (BC), de acordo com a regulamentação do Conselho Monetário Nacional (CMN). Com o início da estruturação regulatória do mercado, buscava-se promover a segurança do ambiente institucional para fortalecer a confiança no mercado, reduzir a assimetria informacional e restringir 
as possibilidades de comportamento oportunista dos agentes. Isto tornaria as instituições mais eficientes na economia dos custos de transação, conforme os argumentos de Williamson (1985) sobre as estruturas de governança das firmas.

Ao longo da consolidação das instituições regulatórias é possível verificar a transferência de modelos institucionais externos para a efetivação no cenário nacional. Segundo Barcellos (2010), as mudanças na estrutura do mercado tiveram como inspiração as instituições norte-americanas, as quais eram o modelo de desenvolvimento da época. Apesar do desenvolvimento significativo das instituições que serviram como inspiração, tanto a sociedade como a economia e a política do Brasil representam um conjunto de especificidades institucionais. Diante disso, a transferência dos modelos externos não se mostrou eficaz, uma vez que houve falhas de adaptação ao contexto nacional. Segundo Carvalho (2014), alguns institutos transferidos foram desvirtuados, principalmente a transformação das Bolsas em personalidades jurídicas, o que não se mostrou eficaz na promoção da competição e crescimento do mercado. Sendo assim, tornou-se necessário o gradual aprimoramento das instituições para a consolidação do mercado acionário nacional.

Após a instituição da Lei do Mercado de Capitais em 1965, o BC solicitou assistência técnica aos Estados Unidos em relação à regulação do mercado de capitais no país. $O$ resultado das visitas foi a elaboração de um relatório com diagnósticos sobre a indústria de investimentos brasileira, o qual apontava a estagnação das Bolsas e de seus membros como consequência da legislação adotada na década de 1890, em que havia pouca fluência do mercado devido aos óbices institucionais. Tal carência estava vinculada à inexistência de uma indústria de subscrição e distribuição de ações, ao formato familiar das firmas, ao padrão enfraquecido de transparência das companhias e ao desprezo destas em relação aos seus investidores. Os consultores americanos também abordam o incentivo à abertura de capital por meio de estímulos fiscais como um passo significativo para a ampliação do mercado, porém o insuficiente nível de transparência das empresas brasileiras era um empecilho ao fomento do investimento privado (POSER; ROTH, 1965). Nesse contexto, todos os esforços privados e governamentais deveriam se concentrar no aumento da confiança do público. Para tanto, era preciso consolidar a base do ambiente institucional com credibilidade e promover a transparência da situação econômica das empresas.

A Lei do Mercado de Capitais de 1965 foi o primeiro passo na adaptação evolutiva das instituições do mercado acionário. Conforme Carvalho (2014), a ampliação do mercado acionário até o início dos anos 70 foi em consequência dos incentivos fiscais e não de suas novas estruturas, visto que ainda não estava difundida no Brasil a compreensão de investimentos em ações. Diante disso, os resultados das inovações institucionais não atingiram a eficiência esperada, impondo a realização de reformas posteriores e a criação de uma autarquia específica para a disciplina do mercado. É evidente, entretanto, que a partir de sua edição foi possível a instalação de estruturas regulatórias capazes de conduzir o mercado e promover o desenvolvimento de suas atividades. Assim sendo, é a partir de 1965 que as instituições regulatórias passaram a ter como objetivo a consolidação do mercado de capitais no Brasil e o seu estabelecimento como fonte de recursos de longo prazo para as empresas. 


\section{Adaptação das Instituições Regulatórias}

As alterações na legislação, a partir da reforma financeira e da criação do regulamento específico ao mercado de capitais, representaram o início da formulação de um ambiente institucional regulatório para a negociação de ações. Apesar do seu aspecto inovador, no entanto, esse mecanismo não foi suficiente para o desenvolvimento do mercado conforme o esperado, o que conduziu à estruturação de um sistema de incentivos fiscais (MATTOS FILHO; PRADO, 2012). Após a promulgação da Lei do Mercado de Capitais em 1965, foram efetivadas diversas resoluções do CMN que, segundo Carvalho (2014), reforçaram as disposições legislativas de 1965 e demonstraram que tais instituições estavam sendo adaptadas a partir da demanda do ambiente, o que reforça a tese de que houve um processo de transformação institucional como apontado por Hayek (1985) e North (1990).

Em relação ao sistema de incentivos fiscais, a disciplina jurídica tinha o objetivo de incentivar a expansão do mercado acionário (MATTOS FILHO; PRADO, 2012). Tal fato indica a condução das conexões de mercado e do desempenho econômico de acordo com o ambiente institucional formulado na esfera legislativa, a qual delimitava a interação dos agentes, assim como enfatiza Hayek (1985) acerca do ordenamento social via um processo seletivo de instituições formais. As mudanças na legislação expandiram o mercado de capitais de forma desordenada, principalmente devido à falta de experiência das companhias e dos corretores. As empresas buscavam os benefícios fiscais, porém não detinham a cultura de abertura de capital, assim como a população não possuía o costume de investir em ações (BARCELLOS, 2010). É nesse contexto que os anos 1970 e 1971 representaram um período de grande especulação nas Bolsas e, diante desse cenário, tem-se o marco de uma das maiores baixas da história das Bolsas brasileiras. Conforme a CVM (2014), o movimento especulativo de 1971 teve curta duração, mas condicionou vários anos de mercado deprimido, pois o evento acarretou grandes prejuízos para um considerável volume de agentes.

Com a reforma do mercado de capitais, a política econômica foi orientada de forma a apressar a consolidação do mercado, incentivando as transações na Bolsa. O resultado dessa política, todavia, constituiu em uma bolha especulativa (MACARINI, 2008). Apesar do apoio oficial ao mercado de capitais, este mostrou-se inexpressivo até 1968, momento no qual se inicia a expansão do volume de transações por meio da injeção de recursos, da expansão originada pelo "milagre econômico" e da atratividade que o investimento em valores mobiliários demonstrava no período. Tal cenário conduziu ao ambiente propício para o surgimento da fase especulativa, cuja magnitude demonstrou os riscos que a política econômica aceitou correr a partir de 1968 na busca pela rápida maturação do mercado (MACARINI, 2008). Isto resultou em uma crise de confiança por parte dos investidores, o que tornou ineficaz a ação da política econômica pretendida com a reforma de 1965.

Uma vez que a confiança no mercado foi abalada, a crise especulativa denegriu a reputação do mercado acionário de forma duradoura (CVM, 2014). Conforme Mattos Filho e Prado (2012), a perda dos investimentos impactou, sobretudo, os investidores não profissionais, os maiores afetados em uma época em que o sistema de informações das companhias emissoras era inadequado, o que aumentava a assimetria informacio- 
nal e o comportamento oportunista dos agentes. Este conjunto de interações, conforme descrito por Williamson (1985), aumentaria os custos de transação dispostos no mercado. Mesmo com a consolidação de um sistema regulatório a partir de 1965, as constantes alterações legislativas prejudicavam a estabilidade e a segurança institucional, visto que as normas eram modificadas ano a ano. Além disso, a crise especulativa de 1971 evidenciou a necessidade de aperfeiçoamento dos mecanismos de proteção aos investidores. Da mesma forma, o ambiente institucional foi criticado pela percepção de que o $B C$ deveria ser substituído por um órgão especializado para fiscalizar o mercado de capitais (CARVALHO, 2014).

Em meio ao cenário de estagnação e tentativa de recuperação do mercado acionário, ocorre o segundo ciclo de reformas institucionais a partir de 1976 (Quadro 2). Tais reformas indicam que, apesar do aspecto inovador, a estrutura consolidada pelas reformas de 1965 acabou por se tornar disfuncional. Conforme Carvalho (2014), os investidores institucionais ainda eram iniciantes, existia a conglomeração bancária como empecilho à independência do mercado de capitais em relação ao sistema bancário comercial, e, além disso, o BC estava sobrecarregado pelo excesso de funções atribuídas pela reforma do Sistema Financeiro, o que reduzia a atenção do órgão regulador sobre as Bolsas e negociações. Desse modo, em 1974 inicia-se um projeto de diretrizes para a reforma da Lei das Sociedades Anônimas com base em uma fusão entre o Direito europeu continental e princípios jurídicos anglo-saxões. Com esse aspecto, novamente ocorre a transferência de um modelo institucional externo para a adaptação no cenário nacional, o que, conforme North (1990), nem sempre produz os resultados esperados. Representando o segundo ciclo de reformas do mercado acionário, a Lei das S/A é reformulada juntamente com a criação da Comissão de Valores Mobiliários (CVM) em 1976, o que institui um órgão promotor e fiscalizador do mercado de capitais. Conforme o Quadro 2, ainda ocorrem novas reformas legislativas em 1997 e 2001, o que indica a constante adaptação institucional do ambiente.

Quadro 2 - Ciclo de Reformas Institucionais do Mercado de Capitais no Brasil

\begin{tabular}{|c|c|c|c|c|c|c|c|}
\hline 1964 & 1965 & 1967 & \multicolumn{3}{|c|}{1976} & 1997 & 2001 \\
\hline Lei n. 4.595 & $\begin{array}{c}\text { Lei } \\
\text { n. } 4.595\end{array}$ & $\begin{array}{c}\text { Decreto } \\
\text { n. } 157\end{array}$ & $\begin{array}{c}\text { Resolução } \\
\text { n. } 366\end{array}$ & $\begin{array}{c}\text { Lei } \\
\text { n. } 6.404\end{array}$ & $\begin{array}{c}\text { Lei } \\
\text { n. } 6.385\end{array}$ & $\begin{array}{c}\text { Lei } \\
\text { n. } 9.457\end{array}$ & $\begin{array}{c}\text { Lei } \\
\text { n. } 10.303\end{array}$ \\
\hline $\begin{array}{c}\text { Estruturação } \\
\text { do Sistema } \\
\begin{array}{c}\text { Financeiro } \\
\text { Nacional }\end{array}\end{array}$ & $\begin{array}{c}\text { Lei do } \\
\text { Mercado }\end{array}$ & $\begin{array}{c}\text { Incentivos } \\
\text { fiscais para a } \\
\text { capitalização } \\
\text { das empresas }\end{array}$ & $\begin{array}{c}\text { Disciplina } \\
\text { o mercado } \\
\text { aberto }\end{array}$ & $\begin{array}{c}\text { Lei das } \\
\text { S/A }\end{array}$ & $\begin{array}{c}\text { Comia a } \\
\text { de Valores } \\
\text { Mobiliários }\end{array}$ & $\begin{array}{c}\text { Reforma na } \\
\text { Lei das S/A }\end{array}$ & $\begin{array}{c}\text { Reforma na } \\
\text { Lei das S/A }\end{array}$ \\
\hline
\end{tabular}

Fonte: Elaborado pelos autores.

A partir de 1980, com o fim do regime militar e a introdução do Plano Cruzado, os investidores redescobriram a atratividade das bolsas de valores (BARCELLOS, 2010). O cenário macroeconômico brasileiro, porém, estava desequilibrado e o país experimentaria novos planos econômicos mediante consecutivos pacotes de medidas para o controle inflacionário. Ao longo da década de 90 o cenário foi condicionado com a abertura da economia, ciclo de privatizações, em que os recursos dos investidores internacionais passaram a ser consideráveis no mercado acionário brasileiro. Conforme Barcellos 
(2010), a estabilização da economia abriu novas perspectivas de desenvolvimento a partir do capital estrangeiro, o que permitiu que algumas empresas brasileiras acessassem o mercado externo para sua capitalização. Ao promover suas ações nas Bolsas norte-americanas, as companhias brasileiras foram obrigadas a seguir as regras relacionadas aos aspectos contábeis de transparência e divulgação de informações, princípios de governança corporativa que Souza (2005) salienta ter alcançado as demais economias por força da globalização.

A melhoria do ambiente econômico e institucional, assim como a abertura comercial e liberalização financeira promovem o desenvolvimento do mercado de capitais (LAW; HABIBULLAH, 2009). Até a década de 90, o mercado de capitais brasileiro não apresentava um nível de eficiência informacional adequado, possuía baixa liquidez, grande concentração do volume negociado em poucos investidores e uma regulação operacionalmente deficiente. A maior integração econômico-financeira após a instituição do Plano Real, no entanto, passou a exigir a adaptação das organizações a novos contextos de mercado, o que, conjuntamente com a relativa estabilidade econômica, reestruturação e concentração patrimonial, maior participação de investidores individuais e estrangeiros, e uma maior transparência nas negociações, melhorou a eficiência do mercado de capitais no Brasil (FORTI; PEIXOTO; SANTIAGO, 2009).

Por meio do ciclo de privatizações dos anos 90, a edição da Lei n. 9.457/1997 provocou mudanças tópicas na Lei das $S / A$, visando à flexibilização de alguns de seus institutos para facilitar o processo de privatização e restruturação empresarial. Diante de tais medidas, a reforma na lei foi encarada com insatisfação, o que conduziu à ideia do Novo Mercado como uma iniciativa de autorregulação da Bovespa com base nas boas práticas de governança corporativa (CARVALHO, 2014). Nesse momento, a Bolsa antecipava-se ao crescimento de suas operações de forma diferente ao empregado na expansão dos negócios em 1971 e no crescimento dos investimentos estrangeiros dos anos 90. Por isso, nos anos 2000, o crescimento do sistema de capitais estaria fundamentado nas normas de governança corporativa, prevenindo o incremento das negociações do mercado de forma ordenada (BARCELLOS, 2010).

O Novo Mercado foi instituído como uma inovação institucional, o que, segundo Carvalho (2014), ultrapassou as reformas societárias legislativas, pois representou uma transformação empresarial privada, uma vez que esta se adequava às melhores práticas de governança corporativa para estimular a eficiência operacional e a economia dos custos de transação. Isto criou um vínculo entre as fontes de capital e o processo interno da firma, tal como os mecanismos de governança salientados por Williamson (1996). Nesse contexto, em 2001 ocorre uma nova reforma na Lei das S/A, com regulamentações que introduziram alterações significativas nas leis de 1976.0 objetivo inicial da reforma era o fortalecimento do mercado de capitais, mediante o estabelecimento de um sistema de maior proteção aos acionistas minoritários, bem como a incorporação dos princípios de boas práticas de governança corporativa (CARVALHOSA; EIZIRIK, 2002). Com a reforma na Lei das S/A em 2001 ocorre o marco no avanço das práticas de governança no mercado de capitais, a partir da tentativa de diminuir a concentração acionária do mercado, tornando-o mais acessível ao pequeno investidor por meio da redução dos riscos aos acionistas minoritários e do aumento de sua participação no controle da empresa (VIEIRA; MENDES, 2004). 
Com o passar do tempo o mercado de capitais brasileiro perdeu espaço para outros mercados devido à falta de proteção ao acionista minoritário e à incerteza em relação às aplicações financeiras, por meio da desconfiança disposta no mercado (CVM, 2014). A falta de transparência na gestão e a ausência de instrumentos adequados de supervisão das companhias influenciaram a percepção de risco e aumentaram o custo de capital das empresas. Sendo assim, os mecanismos de governança passaram a ser aplicados como meio de expandir a confiabilidade do mercado, aumentar a eficiência com que este desempenha o seu papel e assegurar o desenvolvimento de suas atividades (BARCELLOS, 2010). Este cenário indica que, apenas nos anos 2000, com os princípios de governança corporativa, que os aspectos descritos no relatório de Poser e Roth (1965) a respeito da transparência empresarial, autorregulação e incremento da confiança, constituíram-se como uma estratégia à expansão dos valores mobiliários e à economia dos custos de transação.

A partir disso, as reformas legislativas promoveram a gradual adaptação das instituições formais aos aspectos específicos da dinâmica brasileira. As instituições informais, contudo, baseadas na ausência do costume em investimentos no mercado de capitais, aliadas às dificuldades políticas e macroeconômicas do final do século 20 , como também às mudanças contínuas nas normas que disciplinavam o ambiente, foram condições que não repassavam a confiança necessária à consolidação de uma indústria acionária no país, determinando os limites à expansão do mercado. Isto demonstra que o modelo de estrutura do mercado de capitais, ao longo de sua trajetória, esteve vinculado à evolução das instituições jurídicas, visto que a ordenação social formula normas específicas a cada ambiente, como exposto por Sztajn e Gorga (2005). Para evidenciar essa relação é apresentada na sequência a expansão do mercado diante da evolução institucional e suas alternativas ao cenário empresarial.

\section{O Mercado de Capitais como Alternativa ao Desenvolvimento Empresarial}

A construção e evolução gradual do ambiente regulador do sistema de capitais mostraram-se determinantes à expansão do mercado. Assim sendo, como forma de evidenciar a linha de pensamento, pode-se comprovar o desempenho do mercado de capitais a partir da série histórica do Índice Ibovespa no período de 1968 a agosto de 2015 (Gráfico 2). O Índice Ibovespa apresenta o resultado de uma carteira teórica de ativos, sendo o indicador do desempenho médio das cotações dos ativos de maior representatividade do mercado de ações brasileiro (BM\&FBOVESPA, 2015). Para efeito de análise, a série histórica está ajustada conforme a atual metodologia de divulgação.

As oscilações presentes no Índice Ibovespa demonstram, ao longo do tempo, a expansão da atuação do mercado de capitais como mecanismo de capitalização e financiamento das firmas. Os preços das ações podem variar por fatores internos relacionados à empresa ou por fatores externos, tais como o quadro macroeconômico e político, o crescimento do país, nível de emprego e taxa de juros (BM\&FBOVESPA, 2015). Por isso, o desempenho do Ibovespa demonstra o efeito dos fatos macroeconômicos sobre o mercado de capitais, uma vez que estes afetam o cenário econômico e, em consequência, as firmas que nele operam. Dessa forma, o lbovespa mostrou-se em tendência crescente, com exceção do período de queda e estagnação entre 1971 e 1973 devido à 
crise financeira. A partir de então, o crescimento do Índice também pode ser visualizado com a criação da CVM e o desenvolvimento da Lei das S/A em 1976, momento no qual a mudança institucional incrementa a confiabilidade no mercado, de forma a promover uma segurança jurídica superior ao que era aplicado até então.

Gráfico 2 - Índice Ibovespa 1968-2015

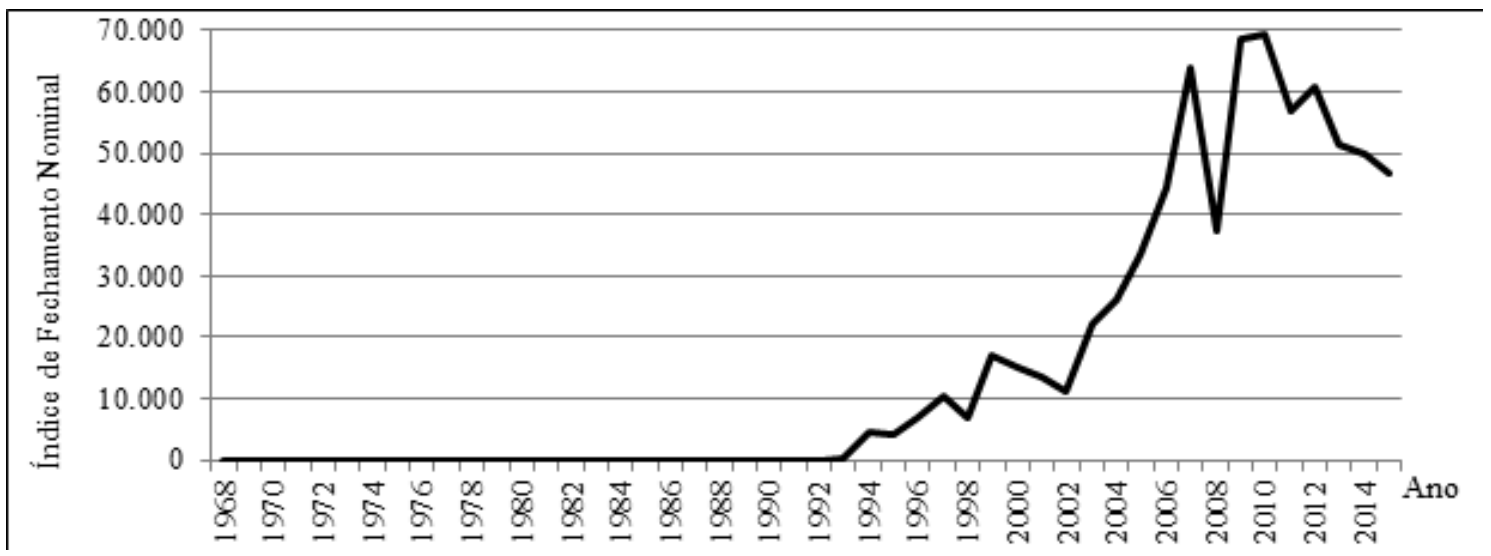

Fonte: BMF\&BOVESPA (2015).

Apesar das mudanças institucionais proporcionadas pelo segundo ciclo de reformas legislativas sobre o mercado de capitais, o desempenho do lbovespa não apresentou crescimento significativo até 1984 . No cenário político, 1985 é marcado como o fim do regime militar no Brasil, no entanto, no cenário macroeconômico, a década de 80 é caracterizada pelas instabilidades, com volatilidade e insegurança jurídica, devido às fragilidades da economia brasileira e ao fato de a legislação se mostrar ineficiente em certos aspectos, uma vez que alguns de seus institutos foram adaptados à realidade brasileira de forma ineficiente (BARCELLOS, 2010). Conforme exposto por Barcellos (2010), a CVM não conseguia impor a efetivação das normas legislativas, como também o sistema financeiro e o mercado de capitais não estavam correlacionados como instrumentos para financiar investimentos privados. Estes entraves dificultavam o desenvolvimento do mercado, uma vez que afetavam o desempenho da economia como um todo.

Uma vez restabelecida a democracia no cenário político, esperava-se um impulso na atividade econômica, de forma a promover o mercado de capitais como uma alternativa eficaz de financiamento para as empresas. O cenário macroeconômico brasileiro na década de 80 , contudo, impossibilitava a expansão da atuação do mercado, visto os desequilíbrios nacionais. Com essa conjuntura, no início da década de 90 são estabelecidas políticas de intensificação da abertura econômica e de privatizações, sendo que, apenas em 1994, inicia-se o processo de estabilização econômica por meio do Plano Real. Segundo Barcellos (2010), no período de 1991 a 1994 o comportamento dos fluxos de capital expandiu-se de forma significativa, com crescimento nos investimentos e nas transações presentes nas Bolsas.

O investimento direto estrangeiro nas Bolsas brasileiras fez com que os negócios aumentassem significativamente (BARCELLOS, 2010). A expansão do Ibovespa ocorre a partir de 1990 com a abertura econômica e, sobretudo, após 1994 com a estabilização macroeconômica. Conforme Möller e Callado (2007), o influxo de capitais externos ao mercado brasileiro exerceu influência preponderante sobre o lbovespa, uma vez que a 
capitalização nacional ainda se mostrava pequena diante das necessidades de estrutura de capital das firmas. A partir da abertura econômica são visíveis as interferências promovidas pelas crises financeiras de âmbito internacional e nacional sobre o mercado brasileiro de ações, demonstrando a volatilidade do capital estrangeiro ante o aumento do risco. No Gráfico 2 é possível identificar momentos de retração do Ibovespa diante das crises, as mais significativas em 1997, pela retração dos mercados emergentes; 2000 a 2002 em virtude das condições instáveis no período de eleições nacionais e transição de governos (MÖLLER; CALLADO, 2007); 2008 ante a crise financeira deflagrada no mercado norte-americano e sua dispersão pela economia mundial, de forma que há uma tendência de decréscimo no cenário econômico desde então, apesar do aparente incremento em 2010. Tal tendência intensificou-se com a instabilidade política e econômica presente no Brasil a partir de 2014.

Ao longo da evolução do mercado de capitais brasileiro, esta demarcada pelo processo de consolidação institucional do ambiente, a capitalização nacional mostrou-se pequena diante da estrutura de capital das firmas, como apresentado por Möller e Callado (2007). Sendo assim, o financiamento empresarial não mantinha alternativas de governança para a gestão de investimentos, visto que o cenário do mercado foi conturbado pelos baixos níveis de confiabilidade das transações e pelas características estruturais da economia brasileira. A demanda do mercado de capitais por transparência, tratamento equânime para os acionistas e uma estrutura de conselho adequada configurou-se como pontos importantes em prol do crescimento e da diversificação do sistema financeiro (VIEIRA; MENDES, 2004). Isto estabeleceu o Nível 1, Nível 2 e o Novo Mercado como uma inovação no sistema de regulação das firmas ao aderirem à conduta da boa governança de forma voluntária (CARVALHO, 2014). Com o incremento dos princípios da governança nas companhias brasileiras, buscou-se promover a confiança no mercado, como também proporcionar a economia dos custos de transação e a meIhor estrutura de organização interna das empresas.

\section{CONCLUSÃO}

O arranjo institucional tem a competência de organizar o meio social e o sistema econômico, direcionando a eficiência alocativa dos recursos enquanto ordena o comportamento dos atores sociais, suas interações e os custos de funcionamento do mercado, conforme já enfatizado por Coase (1937) e Williamson (1985). Sendo um sistema em constante transformação, a interação entre o ambiente político institucional, a estrutura de governança das firmas e o meio jurídico e social representa uma dinâmica específica a cada sociedade, conforme a perspectiva da historiografia econômica de North (1990).

A evolução do mercado de valores mobiliários no Brasil pode ser analisada em tal contexto. Na sua trajetória histórica, o mercado de capitais passou por momentos instáveis, o que acabou por moldar o processo empresarial. Em relação à constituição do mercado de capitais brasileiro, este foi condicionado pelos aspectos estruturais da formação econômica e política do país. $\mathrm{O}$ ambiente restritivo já descrito permaneceu até 1965, quando ocorre o marco de uma estrutura favorável ao mercado, por meio da edição da Lei do Mercado de Capitais, cujo arranjo fortaleceu-se em 1976, no segundo ciclo de reformas institucionais com a criação da CVM. Apesar das inovações institu- 
cionais, o quadro macroeconômico desequilibrado dos anos 80 prejudicava o sistema acionário. Com a abertura aos investimentos estrangeiros e a estabilização econômica, propiciou-se que os negócios crescessem a partir da entrada de capitais externos, contudo isso conduziu à vulnerabilidade diante de crises internacionais e escândalos corporativos, o que incentivou a adoção de boas práticas de governança nos anos 2000 como pilar do desenvolvimento do mercado.

Ao longo de sua história, a evolução das instituições desempenhou papel preponderante à construção, atrofia e crescimento do mercado de capitais, fato que reduziu as possibilidades de estrutura de governança para as empresas e, consequentemente, afetou o desenvolvimento empresarial brasileiro, o que vai ao encontro dos argumentos da Nova Economia Institucional (COASE, 1937; WILLIAMSON, 1985, 1996; NORTH, 1990) em relação aos efeitos das instituições sobre o sistema econômico. No momento em que se iniciava uma expansão às negociações por meio do mercado de capitais, foram impostas normas formais após as crises de 1857 e 1891 que acabaram por se tornar óbices ao crescimento das Sociedades Anônimas. Esse quadro não fomentou uma indústria acionária no país, uma vez que, com o processo de industrialização em curso, não existia uma cultura de investimentos. Essas condições, como características particulares da sociedade brasileira, inibiram os resultados das inovações institucionais propostas a partir de 1965. Por meio do processo adaptativo das instituições, conforme descrito por North $(1990,2005)$ e Acemoglu e Robinson (2012) de forma específica a cada sociedade, sua evolução constante foi moldando a realidade empresarial no Brasil, em que o ordenamento jurídico representou o principal mecanismo regulador das relações econômicas (HAYEK, 1985). Por mais que se identifiquem as instituições ineficientes e seus entraves, no entanto, o processo de mudança social ocorre gradativamente e está sujeito aos interesses de grupos que perpetuam tais instituições. Atualmente, a definição de regras de governança corporativa que formaram o chamado Novo Mercado representa uma evolução institucional na qual se deposita a confiança no mercado de capitais como forma de incentivo ao desenvolvimento empresarial no Brasil.

\section{REFERÊNCIAS}

ACEMOGLU, D.; ROBINSON, J. A. Por que as nações fracassam: as origens do poder, da prosperidade e da pobreza. Rio de Janeiro: Elsevier, 2012.

ALCHIAN, A. A.; DEMSETZ, H. The Property Right Paradigm. The Journal of Economic History, v. 33, n. 1, p. 16-27, 1973.

ANTONACOPOULOU, E.; CHIVA, R. The social complexity of organizational learning: the dynamics of learning and organizing. Management Learning, v. 38, n. 3, p. 277-295, 2007.

ARTHUR, W. B. Increasing returns and path dependence in the economy. Ann Arbor: The University of Michigan Press, 1994.

BARCELLOS, M. Histórias do mercado de capitais no Brasil: depoimentos inéditos de personalidades que marcaram a trajetória das bolsas de valores do país. Rio de Janeiro: Elsevier, 2010.

BM\&FBOVESPA. Apresenta informações gerais sobre a instituição. 2015. Disponível em: http://www.bmfbovespa.com.br/pt_br/index.htm\#. Acesso em: 3 out. 2015.

BOTTAZZI, G.; DOSI, G.; REBESCO, I. Institutional Architectures and Behavioral Ecologies in the Dynamics of Financial Markets. Journal of Mathematical Economics, v. 41, p. 197-228, 2005.

CARLSSON, R. Ownership and value creation: strategic corporate governance in the new economy. New York: John Wiley \& Sons, 2001.

CARVALHO, A. G. de. The Effect of Institutions on the External Financing of Brazilian Firms. Revista Brasileira de Finanças, v. 7, n. 1, p. 1-27, 2009.

CARVALHO, N. A saga do mercado de capitais no Brasil. São Paulo: Saint Paul Editora, 2014. 
CARVALHOSA, M.; EIZIRIK, N. A Nova Lei das S/A. São Paulo: Saraiva, 2002.

CASSIMON, D; ENGELEN, P.J. Impact of the Legal and Institutional Framework on the Financial Architecture of New Economy Firms in Developing Countries. Information Economics and Policy, v. 17, p. 247-269, 2005.

CHEUNG, S. N. S. The Contractual Nature of the Firm. Journal of Law and Economics, v. 26, n. 1, p. 1-21, 1983.

COASE, R. H. The Firm, the Market and the Law. Chicago: The University of Chicago Press, 1990.

COASE, R. H. The Nature of the Firm. Economica, v. 4, n. 3, p. 386-405, 1937.

COOTER, R.; ULEN, T. Direito \& Economia. 5. ed. Porto Alegre: Bookman, 2010.

CROSSAN, M. M.; LANE, H. W.; WHITE, R. E. An organizational learning framework: From intuition to institution. Academy of Management Review, v. 24, n. 3, p. 522-537, 1999.

CVM. Comissão de Valores Mobiliários. Mercado de Valores Mobiliários Brasileiro. 3. ed. Rio de Janeiro: CMV, 2014

FORTI, C. A. B.; PEIXOTO, F. M.; SANTIAGO, W. P. Hipótese da eficiência de mercado: um estudo exploratório no mercado de capitais brasileiro. Gestão \& Regionalidade, v. 25, n. 75, p. 45-56, 2009.

FURTADO, C. Formação econômica do Brasil. 34. ed. São Paulo: Companhia das Letras, 2007.

GHERARDI, S. Organizational Knowledge: The Texture of Workplace Learning. Oxford: Blackwell, 2006.

HAYEK, F. A. Direito, Legislação e liberdade: uma nova formulação dos princípios liberais de justiça e economia política. São Paulo: Visão, 1985.

HODGSON, G. M. The evolution of institutional economics. London: Routledge, 2004.

HOFFMAN, A. J. Institutional Evolution and Change: Envrionmentalism and the U.S. Chemical Industry. The Academy of Management Journal, v. 42, n. 4, p. 351-371, 1999.

LAW, S. H; HABIBULLAH, M. S. The Determinants of Financial Development: Institutions, Openness and Financial Liberalisation. South African Journal of Economics, v. 77, n. 1, p. 45-58, 2009.

LEVY, M. B. História da Bolsa de Valores do Rio de Janeiro. Rio de Janeiro: Ibmec, 1977.

LEVY, M. B. "O encilhamento". In: NEUHAM, P. (coord.). Economia brasileira: uma visão histórica. Rio de Janeiro: Campus, 1980.

LIEBOWITZ, S. J.; MARGOLIS, S. E. Path dependence, lock-in, and history. Journal of Law, Economics, \& Organization, v. 11, n. 1, p. 205-226, 1995.

MACARINI, J. P. Um aspecto da política econômica do "milagre brasileiro": a política de mercado de capitais e a bolha especulativa 1969-1971. Estudos Econômicos, v. 38, n. 1, p. 151-172, 2008.

MATTOS FILHO, A. O.; PRADO, V. M. Mercado de Capitais no Brasil. In: LIMA, M. L. L. M. P. (coord.). Agenda contemporânea direito e economia: 30 anos de Brasil. Tomo 2. São Paulo: Saraiva, 2012.

MAYER, C. Financing the New Economy: financial institutions and corporate governance. Information Economics and Policy, v. 14, p. 311-326, 2002.

MÖLLER, H. D.; CALLADO, A. A. C. Investimentos estrangeiros em carteira de ações, crises internacionais e Ibovespa. Revista de Administração Mackenzie, v. 8, n. 1, p. 133-155, 2007.

NORTH, D. C. Institutions, Institutional Change and Economic Performance. Cambridge: Cambridge University Press, 1990.

NORTH, D. C. Understanding the process of economic change. Princeton: Princeton University, 2005.

PETTIGREW, A. M. Context and action in the transformation of the firm. Journal of Management Studies, v. 24, n. 6 , p. 649-670, 1987.

PIERSON, P. Increasing returns, path dependence, and the study of politics. American Political Science Review, v. 94, n. 2, p. 251-267, 2000.

POSER, N. S.; ROTH, A. R. A Preliminary Survey of the Brazilian Stock Markets. Relatório encaminhado ao Banco Central do Brasil. [S.I.: s.n.], 1965. Disponível em: http://www.sechistorical.org/museum/galleries/ imp/imp05b.php\#ftn6. Acesso em: 10 set. 2015.

SILVA, A. L. C. da. Governança corporativa e sucesso empresarial: melhores práticas para aumentar o valor da firma. São Paulo: Saraiva, 2006.

SIMON, H. A. From Substantive to Procedural Rationality. In: LATSIS, S. J. Method and Appraisal in Economics. Cambridge: Cambridge University Press, 1976.

SIMON, H. A. Barriers and bounds to rationality. Structural Change and Economic Dynamics, v. 11, p. 243253, 2000.

SOUZA, T. de M. G. e. Governança corporativa e o conflito de interesses nas sociedades anônimas. São Paulo: Atlas, 2005. 
STRINGHAM, E.; BOETTKE, P.; CLARK, J. R. Are regulations the answer for emerging stock markets? Evidence from the Czech Republic and Poland. The Quarterly Review of Economics and Finance, v. 48, n. 3, p. 541-566, 2008.

SUZIGAN, W. Indústria brasileira: origem e desenvolvimento. São Paulo: Brasiliense, 1986.

SZTAJN, R.; GORGA, E. Tradições do Direito. In: ZYLBERSZTAJN, D.; SZTAJN, R. (org.). Direito \& Economia: análise econômica do direito e das organizações. Rio de Janeiro: Elsevier, 2005.

TAUNAY, A. d'E. O encilhamento: cenas contemporâneas da Bolsa do Rio de Janeiro em 1890, 1891 e 1892. São Paulo: Edições Melhoramentos, 1893.

TORRES FILHO, E. T.; COSTA, F. N. da. Financiamento de longo prazo no Brasil: um mercado em transformação. Rio de Janeiro: Ipea, 2013.

VERSIANI, F. R.; BARROS, J. R. M. de (org.). Formação econômica do Brasil: a experiência da industrialização. São Paulo: Saraiva, 1978.

VIEIRA, S. P.; MENDES, A. G. S. T. Governança corporativa: uma análise de sua evolução e impactos no mercado de capitais brasileiro. Revista do BNDES, v. 11, n. 22, p. 103-122, 2004.

WILLIAMSON, O. E. Mechanisms of Governance. New York: Oxford University Press, 1996.

WILLIAMSON, O. E. The Economic Institutions of Capitalism: Firms, Markets, Relational Contracting. New York: The Free Press, 1985.

ZAJAC, E. J.; WESTPHAL, J. D. The Social Construction of Market Value: Institutionalization and Learning Perspectives on Stock Market Reactions. American Sociological Review, v. 69, n. 3, p. 433-457, 2004.

ZYLBERSZTAJN, D.; SZTAJN, R. (org.). Direito \& Economia: análise econômica do direito e das organizações. Rio de Janeiro: Elsevier, 2005. 